\title{
THE PREVALENCE OF ANAEMIA AND MORBIDITY PROFILE AMONG SCHOOL GOING ADOLESCENT GIRLS OF URBAN KATHMANDU, NEPAL
}

\author{
Tiwari K. ${ }^{1}$
}

Seshadri S.

\section{ABSTRACT:}

A perusal of the literature on anaemia prevalence in Nepal from 1975 onwards highlighted two points: anaemia prevalence is high particularly among women and children and that adolescent girls as a group have not been studied much, in fact, the adolescent period is one of the critical periods for anaemia. The present study assessed prevalence of iron deficiency anaemia and morbidity problems of adolescent girl. The results highlighted anaemia as a public health problem in girls and its prevalence was found to be higher in Brahmins girls as compared to Newars and Chhetries. Eighty-two percent of the girls reported health problems such as aches and pains in the body, infectious morbidities, and weakness and breathlessness. Thus, this female population groups needs to be paid special attention for health promoting intervention program.

Key words: Anaemia, morbidity, adolescent girls.

\section{INTRODUCTION:}

It is reported that 2170 million people are affected worldwide by nutritional anaemia. Out of these, 90\% live in developing countries. Among these developing countries, South East Asia has the highest prevalence of anaemia. ${ }^{1}$ The prevalence of iron deficiency anaemia in developing countries as a whole is $36 \%$ whereas it is only $8 \%$ in developed countries. ${ }^{2}$ The prevalence of anaemia is high in women of reproductive age, $47 \%$ across developing countries, and it worsens to $57 \%$ during pregnancy. ${ }^{3}$ The prevalence of anaemia among rural Nepalese adolescent of both sex was $42 \% .^{4}$

1. Doctoral Student, Dept. of Foods and Nutrition, M.S. University of Baroda 390002, India.

2. Head, Dept. of Foods and Nutrition, M.S. University of Baroda 390002, India.

Address for correspondence : $\quad$ Dr. Kalpana Tiwari, Doctoral Student, Dept. of Foods and Nutrition Subidha Nagar, Tinkune

P.O. Box: 608, Kathmandu, Nepal.

Ph. No.: 471930 / 491259, Email: Sahu@wlink.com.np 
A perusal of the literature on anaemia prevalence

in Nepal from 1975 onwards showed that most studies had focused on women and children., $4,6,7,8$ The prevalence data varied from one study to another which could have arisen in part due to the different haemoglobin cut-off levels used and different methods of estimating haemoglobin. However, the data highlight two points: anaemia prevalence is high in most age groups and adolescent girls as a group have not been studied much. Thus, the present study was carried out with the objectives: to assess prevalence of iron deficiency anaemia and morbidity profile on schoolgoing adolescent girls, aged 10 to 18 years in Kathmandu. Anaemia may be a cause of impaired immune responses resulting in infectious morbidities due to low haemoglobin levels. ${ }^{9}$

\section{STUDY DESIGN AND METHODS:}

The present study was carried out in the Urban areas of Kathmandu District, Central Development Region of Nepal. The Kathmandu District covers an area of $395 \mathrm{Sq}$. Km. with mean household size of 5.3 as per the Central Bureau of Statistics in 1996. ${ }^{10}$ The girls from low and middle income households, were selected through schools that catered to the underprivileged population. Four government-aided schools in Kathmandu City were selected for the study. Before selecting the schools, permission to conduct the study was sought and obtained from Nepal Health Research Council. All girls attending the four schools were enlisted as subjects and a total of four hundred twenty girls aged 10 to 18 years from the four schools were randomly selected after taking consent from their parents.
Socio-demographic data were collected on all subjects at baseline. A structured questionnaire was developed and pre-tested on adolescent girls of a school other than the ones selected for the study. The pre-tested questionnaire was modified after pre-testing and finalized. The demographic status, which consisted of information on ethnic class, family composition, size of the family and the type, per capita income, expenditure on food, education and occupation of parents, type of house, drainage facilities, source of drinking water and toilet facilities and dietary consumption such as tea, non-vegetarian foods, and citrus fruits were also recorded in order to test their relationships with iron status.

For haemoglobin estimation, direct elution of cynmethemoglobin method was used in all the subjects.

Morbidity profile of the subjects was gathered through an interview using a pre-tested and finalized interview schedule. Morbidity data were collected over a reference period of six consecutive school days. The proforma consisted of questions on type of morbidities, episodes and duration of the morbidities. It also consisted of health complain of the girls categorized under three subheadings namely upper respiratory infection (URI), gastrointestinal infection (GI) and infection of skin, eyes and ear. The investigator visited the subjects in school everyday in the morning and asked each student if they had suffered from any illness in the previous day. Daily records for 6 days were kept for each subject from which episode and duration of morbidity was derived later on. An episode of illness was defined as one or more days of a particular morbidity preceded by at least one symp- 
tom-free day. When two or more types of morbidity were experienced by the subjects at the same time, each type of morbidity was recorded as one episode. Duration was defined as the number of days for which the subject reported of a particular morbidity. If two morbidities occurred together, the number of days suffered was taken as duration.

The data on socio-demographic, haemoglobin level, morbidities were analysed using programmes of the Statistical Package for Social Sciences/PC+ and mainly mean, percentage, chi-squire and F-test were computed and interpreted.

\section{RESULTS:}

Using the 1992 FAO/WHO cut-off levels (haemoglobin less than $120 \mathrm{~g} / \mathrm{L}$ as normal) ${ }^{11}$ it was found that $60.5 \%$ subject were anaemic. Out of which, $57.4 \%$ were mildly anaemic and $3.1 \%$ were moderately anaemic and interesting finding was that the severe anaemia was absent.(Table 1) The data

Table 1

Prevalence of degress of anaemia in subjects studied by age group $(\mathrm{N}=420)$

\begin{tabular}{|c|c|c|c|c|c|c|c|c|}
\hline \multirow{3}{*}{ Age group } & \multicolumn{7}{|c|}{ Prevalence of degrees of anaemia } & \multirow{3}{*}{$\begin{array}{c}\text { Mean Hb } \\
\pm S E\end{array}$} \\
\hline & \multicolumn{2}{|c|}{$\begin{array}{l}\text { Normal Hb } \\
\geq 120 \mathrm{~g} / \mathrm{L}\end{array}$} & \multicolumn{2}{|c|}{$\begin{array}{l}\text { Mild Hb } \\
\text { 100-119 g/L }\end{array}$} & \multicolumn{2}{|c|}{$\begin{array}{c}\text { Moderate Hb } \\
70-99 \mathrm{~g} / \mathrm{L}\end{array}$} & $\begin{array}{l}\text { Severe Hb } \\
\text { <70 g/L }\end{array}$ & \\
\hline & $\mathbf{N}$ & $\%$ & $\mathbf{N}$ & $\%$ & $\mathbf{N}$ & $\%$ & $\%$ & \\
\hline $\begin{array}{l}10-13 y \\
(N=107)\end{array}$ & 38 & 35.5 & 66 & 61.7 & 3 & 2.8 & - & $115.4 \pm 8.4$ \\
\hline $\begin{array}{l}13-16 y \\
(N=253)\end{array}$ & 107 & 41.9 & 140 & 55.3 & 7 & 2.8 & - & $117.2+10.1$ \\
\hline $\begin{array}{l}16-18 y \\
(\mathrm{~N}=60)\end{array}$ & 22 & 36.7 & 35 & 58.3 & 3 & 5.0 & - & $116.0 \pm 12.6$ \\
\hline $\begin{array}{c}\text { Total } \\
10-18 \mathrm{y}\end{array}$ & 167 & 39.8 & 241 & 7.4 & 13 & 3.1 & - & \\
\hline
\end{tabular}

Chi-square value for agewise prevalence of anaemia $2.28^{\mathrm{NS}}$

F / Ratio for agewise mean haemoglobin $1.29^{\text {NS }}$

were analysed to determine if mean haemoglobin and the prevalence of anaemia were different for younger and older subjects. No significant differences in the prevalence of anaemia or in mean haemoglobin levels between different age group was observed.

Prevalence of anaemia and mean haemoglobin levels of the subjects by ethnicity are shown in
Table 2. The highest prevalence of anaemia was seen among Brahmins (66.7\%) as compared to $55.4 \%$ in Chhetries and $52.3 \%$ in Newars, although this was not statistically significant. The mean haemoglobin levels however were significantly higher $(\mathrm{p}<0.01)$ in Newars $(119.3 \mathrm{~g} / \mathrm{L})$ and in Chhetries $(117.4 \mathrm{~g} / \mathrm{L})$ as compared to the Brahmins(114.8g/L). 
Table 2

Percent prevalence of different degrees of anaemia by ethnicity $(\mathrm{N}=420)$

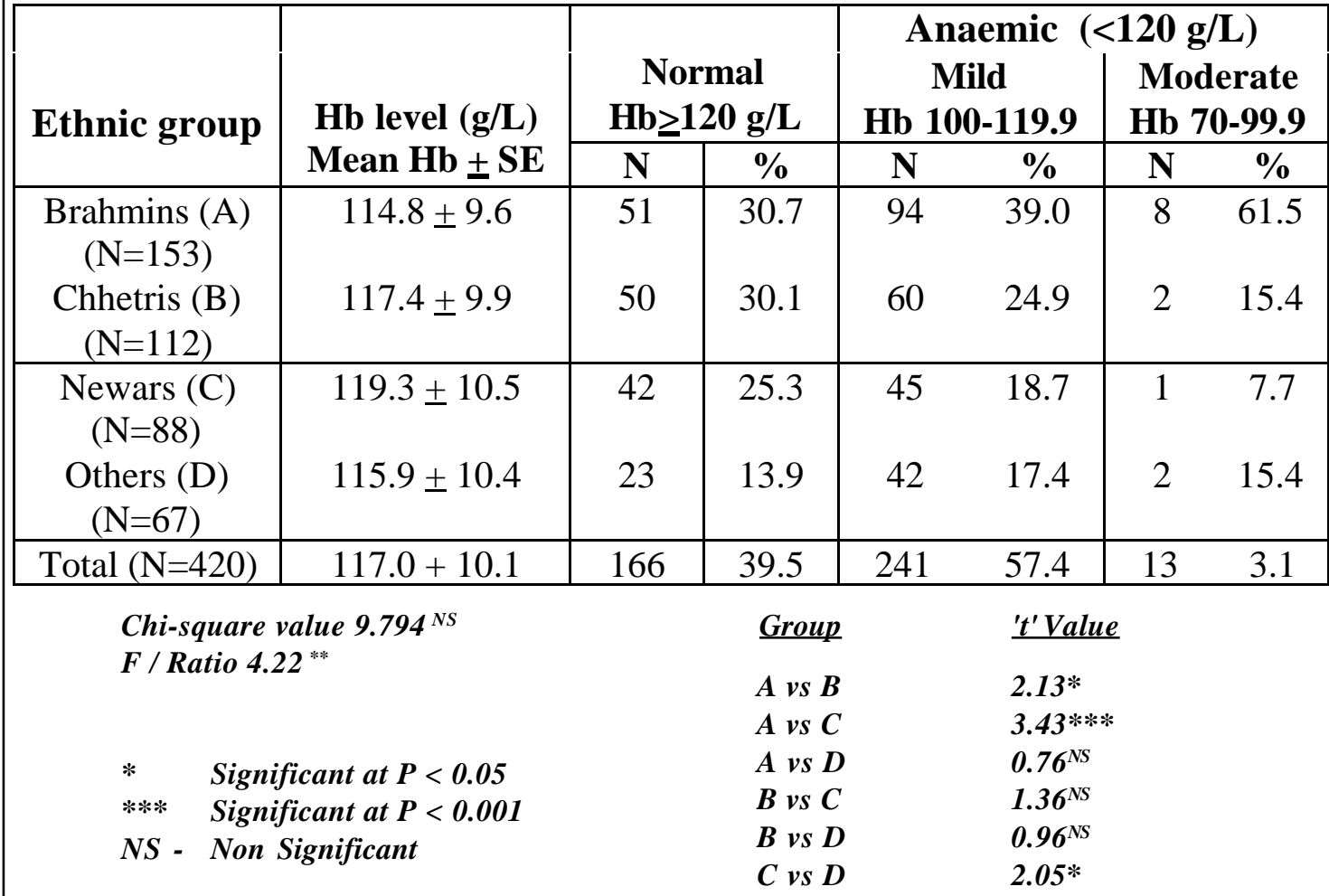

As depicted in Table 3, 82\% reported various types

Table 3

Mean haemoglobin levels (g/L) and number and percent of subjects anaemic and non-anaemic by type of morbidities

\begin{tabular}{ccccccc} 
Type of morbidities & Mean & \multicolumn{2}{c}{ Anaemic } & \multicolumn{2}{c}{ Non-anaemic } \\
& $\mathbf{H b} \pm \mathbf{S E}$ & $\mathbf{N}$ & $\boldsymbol{\%}$ & $\mathbf{N}$ & $\boldsymbol{\%}$ \\
\hline Infectious & $118.0+9.7$ & 77 & 55.8 & 61 & 44.2 \\
Aches and pains & $\begin{array}{c}\mathrm{N}=138) \\
116.3+10.4 \\
(\mathrm{~N}=408)\end{array}$ & 250 & 61.3 & 158 & 38.7 \\
Anaemia related & $\begin{array}{c}118.1 \pm 10.6 \\
(\mathrm{~N}=140)\end{array}$ & 76 & 54.3 & 64 & 45.7 \\
Allergy and bleeding from nose & $\begin{array}{c}117.5 \pm 11.5 \\
(\mathrm{~N}=26)\end{array}$ & 15 & 57.7 & 11 & 42.3 \\
\hline Presence of morbidity & $\begin{array}{c}116.7+5.6 \\
(\mathrm{~N}=345)\end{array}$ & 204 & 80.3 & 141 & 84.9 \\
Absence of morbidity & $\begin{array}{c}116.1 \pm 10.8 \\
(\mathrm{~N}=75)\end{array}$ & 50 & 19.7 & 25 & 15.1 \\
\hline
\end{tabular}

of morbidities such as infectious morbidities, aches and pains, anaemia related complaints and some allergies. Aches and pains topped the list of morbidities with more than $50 \%$ of the girls suffering from this problem. The second highest (33\%) morbidity was anaemia related such as weakness, breathlessness, and tiredness, while $15.7 \%$ reported upper respiratory tract infection.

The haemoglobin levels in relation to morbidity shows neither the prevalence of morbidities nor specific types appeared to have any significant effect on mean haemoglobin level. The data were further analysed to determine if any difference existed in mean duration and mean episode of the morbidities experienced by the anaemic and non-anaemic subjects and the results are reported in Table 4.

Table 4

Anaemia in relation to episodes and durations of morbidity $(\mathrm{N}=420)$

\begin{tabular}{lccc}
$\begin{array}{l}\text { Hb status of } \\
\text { the subject }\end{array}$ & $\mathbf{N}$ & $\begin{array}{c}\text { Mean episode of } \\
\text { morbidities Mean + SE }\end{array}$ & $\begin{array}{c}\text { Mean duration of } \\
\text { morbidities Mean + SE }\end{array}$ \\
\hline Anaemic & 254 & $1.16+0.08$ & $2.91+0.13$ \\
$\mathrm{Hb}<120 \mathrm{~g} / \mathrm{L}$ & & $1.19+0.05$ & $3.18+0.15$ \\
\hline $\begin{array}{l}\text { Non-anaemic } \\
\mathrm{Hb}>120 \mathrm{~g} / \mathrm{L}\end{array}$ & $0.75^{\mathrm{NS}}$ & $1.17^{\mathrm{NS}}$ \\
$\begin{array}{l}\text { 't' Value } \\
\text { NS - Non significant }\end{array}$ & & \\
\end{tabular}




\section{DISCUSSION:}

Four hundred and twenty adolescent girls from four government schools having similar background, were selected because children from lower middle and low income are usually catered by these school. These subjects belonged primarily to lower socioeconomic groups, the average income of the families of these subjects being Rupees 1121 per month, which was not adequate even to have a balanced diet for an average family.

The prevalence of anaemia among the girls was found to be high: $60.5 \%$ as per the epidemiological criteria of suggested by FAO/WHO. ${ }^{11}$ When the cut-off of less than $70 \mathrm{~g} / \mathrm{L}$ was used, none of the subjects was severely anaemic. Thus, anaemia seen in these girls was of a moderate and mild type with haemoglobin in the range of $70 \mathrm{~g} /$ $\mathrm{L}$ and less than $120 \mathrm{~g} / \mathrm{L}$. The highest haemoglobin of the total sample was $117.0 \pm 10.1 \mathrm{~g} / \mathrm{L}$. Agewise mean_haemoglobin level of the subjects in the present study as compared with affluent Indian girls was lower but similar to the prevalence reported for low income rural adolescent girls. ${ }^{12}$ However, prevalence data found to be higher in comparison with Bangladesh $(22 \%)$ and $36 \%$ in SriLanka. ${ }^{13,14}$ The only other study available on adolescent girls in Nepal used a cut-off point of $115 \mathrm{~g} / \mathrm{L}$. If this cut off level is used the prevalence of anaemia in the present study is $39 \%$, as against $42 \%$ reported in the previous study. ${ }^{4}$

The haemoglobin and presence or absence of anaemia in the subjects when analysed in relation to several socio-demographic factors showed that only ethnicity made a difference, with Chheris and Newars showing higher mean haemoglobin and lower prevalence of anaemia . Except ethnicity of none of the socio-economic characteristics tested emerged as variables affecting haemoglobin levels This in these population ethnicity was a major determinant of haemoglobin levels. Further analysis revealed that ethnicity differences were in part due to dietary habits, the Newars \& Chhetries consumed non-vegetarian foods more frequently than Brahmins. This was supported by the analysis of haemoglobin levels of vegetarian versus non-vegetarians subjects with significant difference in mean haemoglobin in the levels of vegetarian i.e. $109 \mathrm{~g} /$ $\mathrm{L}$ and that of non-vegetarians $113.8 \mathrm{~g} / \mathrm{L}$. Relationship between tea drinking, citrus fruit consumption and haemoglobin levels when explored, indicated the expected relationships, that tea inhibits iron absorption and ascorbic acid found in citrus fruits increases iron absorption are well documented..$^{15,16,3}$

Adolescent is generally considered to be characterized as a time of being relatively free of health problems. However, $82 \%$ of the subjects in this study reported one or other type of morbidities: infectious morbidities (32\%) and aches and pains (96\%) anaemia related (33\%) and allergies (5\%). Even considering that self-reported morbidities may tend to overestimate or underestimate the actual incidence and may not necessarily match with clinical diagnosis, ${ }^{17}$ it is still noteworthy that a large proportion of the subjects perceived themselves to be ill with infectious or non-infectious morditities. These definitely need to be corroborated by clinical diagnosis. However, the other studies carried out in Cameroon, ${ }^{18}$ Nepal, ${ }^{4}$ Equador, ${ }^{19}$ and Phillippineo-Mindana ${ }^{20}$ have also reported $60 \%$ of fever with malaria and $47 \%$ of diarrhea among Cameroonians, $15 \%$ of diarrhea and $30 \%$ of upper respiratory tract infection(URTI) among rural Nepalese, $31 \%$ of the diarrhea among Equador and $8 \%$ in Philipino adolescent girls. The interesting finding among Nepalese girls was that the prevalence of all types of morbidities observed in the present study, was higher i.e. more than 50\% among age group 13 to 16 years as compared to younger, 10 to 13 years and older 16 to 18 years 
groups. The reason could be hormonal changes which occurs during adolescence particularly at the time of onset of menarche. Number of episodes and duration of morbidities did not have any significant association with the anaemic and non-anaemic status of the subjects in the present study which could be due to the presence of only mild and moderate anaemia among the studied subjects. Prema et al in 1982 had also reported that morbidities may increase only in the case of severe anaemia, i.e. haemoglobin less than $80 \mathrm{~g} / \mathrm{L} .^{21}$ Sharma in 1996 had also reported that the mean duration of morbidities among Indian pregnant women was lowest in those with haemoglobin level $\geq 110 \mathrm{~g} / \mathrm{L}$ and the highest in those who were severely anaemic i.e haemoglobin levels less than $<70 \mathrm{~g} / \mathrm{L}$. ${ }^{22}$ It may be noted that none in the present study was severely anaemic.

\section{REFERENCES:}

1. Seshadri S (1995). Regional overview of the situational analysis of iron deficiency anaemia for the inter country workshop on iron deficiency anaemia. A report prepared to STC/WHO-SEARO, New Delhi by Dept. of Foods and Nutrition, Faculty of Home Science, M.S. University of Baroda, India.

2. Dubey AP (1995). Iron deficiency anaemia: Epidemiology, diagnosis and clinical profile. In Nutrition in Children: Developing Country Concerns. Sachdev HPS and Choudhury Panna (eds.), Cambridge Press, Kashmera Gate, Delthi.

3. DeMaeyer EM, Dallman P, Gurney JM, Hallberg L, Sood SK and Srikantia SG (1989). Assessment, prevalence and consequences of iron deficiency anaemia through primary health care, WHO, Geneva.
4. Regmi SC and Adhikari RK (1994). A study on the factors influencing nutritional status of adolescent girls in Nepal. Nutrition of Adolescent Girl's Reaearch Program No.6 ICRW, Washing ton, DC.

5. HMG/USAID (1975) . Nepal Nutrition Status Survey, Kathmandu, Nepal

6. JNSP ( 1988). A baseline survey for the Joint Nutrition Support Programme, New ERA/ Kathmandu, Nepal.

7. Chhetri MK, Weise Z, Shrestha S and Tiwari K (1994). Anaemia in Pregnant women in Nepal; Strategies to improve compliance with iron supplementation. WHO/MOH/Dept. of Health Services, Kathmandu , Nepal.

8. Dreyfuss ML , Shrestha JB, Khatry SK, Shrestha SR, Dali SM, Adhikari RK and Pokhrel RP (1997). The prevalence of anaemia among pregnant and lactating women and among their infants in Sarlahi district. Journal of Nepal Medical Association 35 (122):234-240.

9. WHO (1968). Nutritional Anaemias. Technical Report Series No. 405 ,WHO, Geneva.

10. Central Bureau of Statistics/National Planning Comission /HMG-Nepal (1996). Statistical pocket book. Central Bureau of Statistics, NPC/HMG, Nepal.

11. FAO/WHO (1992). International conference on nutrition:Major-issues for nutrition stratigies, Food and Agriculture Organization and WOrld Health Organization ,Theme paper no.6:12. 
12. Seshadri S (1997). Oral iron supplementation to control anaemia in adolescent girls: Community trials of effectiveness of daily versus weekly supplementation. Dept. of Foods and Nutrition/UNICEF-India.

13. Medical Research Institute/WHO(1998). Daily versus weekly iron supplementation effects on adolescent school girls, Ministry of Health and Indigenous Medicine, Dept, O Nutrition, SriLank.

14. Ahmed F, Khan MR, Jaj S, Hyderi T, Farque MO, Margetts BM, Jackson AA (1997). Serum retinal and biochemical measures of iron status in adolescent school girls in urban Bangladesh. European Journal of Clinical Nutrition 50 (6):346-351.

15. Stoltzfus and Dreyfuss (1998). Guidelines for the use of iron supplements to prevent and treatment iron deficiency anaemia. International Nutritional Anaemia Counsultative Group (INACG),WHO/UNICEF.

16. Anand a and Seshadri S (1993). Role of citric acid in influencing in vitro availability of iron:Implications for iron nutrition. Journal of Food Science Technology: 30(5);371-373.

17. Kurz KM and Johnson-Welch C (1994). The nutrition and lives of adolescents in developing countries: Findings from the nutrition of adolescent girls research program ,ICRW/ USAID,USA.
18. Kurz KM and Ngo JS (1994). Study of the factors that influency the nutritional status of adolescent girls in Camaroon. International Centre fro Research on women, Nutrtion of Adolescent Girl's Research Program No. 10.

19. de Grijalva and I Grijala (1994). Improving Nutrtional Practices of Equadoren Adolescents girl's Research Program NO .11.

20. Bouis He, Palabrica-Costello M, Solonc and Limbo AA (1994). Understanding gender differenctiated constraints to Philippine form household investvents in adolescents: Implications for their nutritional status,ICRW, Nutrition of adolescent Girl's Research Programmed, No. 7 ,Washington D .C.

21. Prema K, Ramalaksmi BA, Madhavapeddi R and Bahu S (1982). Immune Status of anaemia pregnant women .Brit J Obs Gynec 89: 222-25

22. Sharma K (1997). Studies on nutritional anaemia and the nutritional anaemia control programmed in an urban slum setting in India with special reference to pregnant women, lactating women and preschool children (26y). Ph.D. Thesis, Dept. of Foods and Nutrition, M.S. University of Baroda, India.

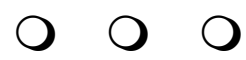

